\title{
光遥控石墨烯蜘蛛机器人
}

\author{
韩冰 $^{1,2}$, 张永来 ${ }^{2}$, 孙洪波 ${ }^{*}$
}

1. 清华大学精密仪器系, 精密测试技术及仪器国家重点实验室, 北京 100084 ;

2. 吉林大学电子科学与工程学院, 集成光电子学国家重点实验室, 长春 130012

* 联系人, E-mail: hbsun@tsinghua.edu.cn

\section{Remote light control of graphene spider robot}

\author{
Bing Han ${ }^{1,2}$, Yong-Lai Zhang ${ }^{2} \&$ Hong-Bo Sun ${ }^{1 *}$ \\ ${ }^{1}$ State Key Laboratory of Precision Measurement Technology and Instruments, Department of Precision Instrument, Tsinghua University, Beijing 100084, \\ China; \\ ${ }^{2}$ State Key Laboratory of Integrated Optoelectronics, College of Electronic Science and Engineering, Jilin University, Changchun 130012, China \\ *Corresponding author, E-mail: hbsun@tsinghua.edu.cn \\ doi: 10.1360/TB-2020-0755
}

机器人被誉为“制造业皇冠顶端的明珠”, 承载着人类 对高度智能化生活的憧憬和向往. 早在 1920 年, “机器人” 一词首次在科幻剧本《罗萨姆的万能机器人》中提出, 随 即在生产生活、科学技术、社会伦理等方面都引发了众多 变化. 特别地, 近些年关于机器人题材的科幻书籍、电影 创作备受人们喜爱. 与此同时, 也激发了人们对机器人更 细致和深刻的探索. 大自然是人类最好的老师, 大多数机 器人的设计都源自对生物运动的模仿, 如仿生壁虎、蝙蝠、 蜘蛛、蜻蜓等机器人的成功制造, 为机器人的实际应用带 来曙光.

自然界中生物的各种运动离不开关节周围的肌肉不 断发生收缩以及舒展的过程. 在仿生机器人以及运动辅助 仪器的设计中, 模仿肌肉作用的驱动部位是实现运动的关 键. 目前, 驱动器方面的研究集中于对驱动方法 (如电动、 气动、液动)或是环境刺激(如光、湿度、磁场)的控制 ${ }^{[1 \sim 4]}$. 目 前的仿生机器人多采用电驱动方式, 这需要集成能源供给 部件, 或者外接电源装置, 使得系统在小型化方面受到制 约. 刺激响应型驱动器则可以有效避免这类问题. 例如, 光驱动就是一种仿生机器人理想的操控方式, 它可以通过 非接触式的能量供给实现对仿生器件人遥控操作. 然而, 开发光控的仿生机器人也同时面临诸多难题. 首先, 光响 应执行器形变简单, 为实现复杂的机械运动, 研究者需要 集成众多驱动器及配件, 并进行精确的组装, 这一过程涉 及制作工艺的复杂性、设计原理的可行性, 成本等诸多问 题. 更重要的是, 光驱动器的能量转化效率不高, 为了提 升器件敏感特性需要在材料光吸收、光选择性、光热效应、 热传导和机械能转化等多个方面综合优化材料性能. 上述
难题成为制约光遥控仿生机器人发展的关键. 为此, 吉林 大学张永来教授、清华大学孙洪波教授团队 ${ }^{[5]}$ 共同探索, 巧妙地解决了这些难题, 无须集成组装过程就实现了复杂 的肢体动作和多足运动, 相关研究成果已在 Advanced Materials 发表.

石墨烯材料具有良好的导热性与柔韧性、超高的机械 强度和良好的吸光能力, 是一种光控柔性机器人的绝佳制 造材料. 其规则的蜂窝状原子排布, 让声子热能在二维平 面内得到迅速地扩散. 相比之下, 石墨烯氧化物由于原子 蜂窝状排布被破坏，含氧官能团的存在让热能在整个平面 内的传导受阻. 因此将石墨烯与其氧化物材料进行图案化 设计, 可以在平面内形成导热性能的差异性分布.

激光还原石墨烯氧化物的方法, 可以实现对材料导热 性能的调控. 石墨烯氧化物具有较好的光热转化效率, 能 够在较低的激光功率下发生光热还原过程, 实现对石墨烯 二维结构的修复. 激光扫描过的区域, 含氧官能团以气体 的方式进行脱除, 得到还原的石墨烯氧化物材料. 且激光 直写是一个无掩模加工过程, 可以对加工路径进行设计, 实现图案化还原. 在机器人的设计过程中, 可以让“关节” 部位材料的导热性能升高, 有利于实现光热转化.

为了改善石墨烯氧化物材料的激光还原程度, 以及提 高材料光热响应效率, 将金纳米棒与石墨烯氧化物进行复 合. 金纳米棒材料根据不同的长径比, 其表面等离子体在 受到与其共振吸收峰位相同的光源照射时, 将发生等离子 体共振. 此时金纳米棒材料的光热转化效率达到最高, 提 升了复合材料整体的光热转化效率.

实验中机器人的驱动主要基于传统的“双金属片”模 
型, 即将两种具有不同的热膨胀系数材料进行结合. 当器 件置于不同的温度条件下, 两种材料受温度影响体积变化 程度产生差异, 从而发生弯曲偏转. 在本实验中将石墨烯 氧化物与金纳米棒复合材料 (热膨胀系数较小), 与具有较 大热膨胀系数的聚合物 PMMA 材料相结合, 就可以控制 光热转化效率, 实现弯曲角度可控的驱动设计. 利用激光 局部还原石墨烯氧化物材料, 还原与未还原区域材料导热 性质的差异, 将导致还原区域材料迅速升温, 弯曲程度大 大提高, 形成类似肌肉牵拉作用的关节弯曲效果. 此外, 金纳米棒材料独特的波长选择特性, 为光驱动方法提供了 除光强、时间外另一维度的调控方法, 即波长调控. 将掺 人不同吸收波长的金纳米棒材料进行设计, 就可实现不同
“关节”部位的选择性弯曲.

光遥控石墨烯机器人巧妙地结合了金纳米棒材料的 波长选择特性和石墨烯氧化物材料可设计的热传导能力, 形成了可以灵活操控的仿生肌肉设计. 利用激光图案化还 原, 可以实现机器人超低成本的制备. 成功制作了微型仿 生蜘蛛、仿生捕蝇草和仿生手指, 并进行激光远距离操控. 激光可以诱导蜘蛛腿部关节进行弯曲变形, 当激光顺次对 八条腿进行弯曲控制时, 蜘蛛机器人就实现了爬行运动过 程. 上述机器人的成功制备和精细操控, 充分体现了激光 加工和激光操控的灵活性. 该工作对微型仿生机械运动提 供了巧妙的光控设计理念, 为机器人的远程控制起到重要 推动作用.

\section{推荐阅读文献}

1 Christianson C, Goldberg N N, Deheyn D D, et al. Translucent soft robots driven by frameless fluid electrode dielectric elastomer actuators. Sci Robot, 2018, 3: UNSP eaat1893

2 Belding L, Baytekin B, Baytekin H T, et al. Slit tubes for semisoft pneumatic actuators. Adv Mater, 2018, 30: 1704446

3 Shepherd R F, Ilievski F, Choi W, et al. Multigait soft robot. Proc Natl Acad Sci USA, 2011, 108: 20400-20403

4 Han B, Zhang Y L, Chen Q D, et al. Carbon-based photothermal actuators. Adv Funct Mater, 2018, 28: 1802235

5 Han B, Zhang Y L, Zhu L, et al. Plasmonic-assisted graphene oxide artificial muscles. Adv Mater, 2019, 31: e1806386 